\title{
DEL DESARROLLO SOSTENIBLE A LA SUSTENTABILIDAD AMBIENTAL ${ }^{*}$
}

\author{
JENNIFER LORENA GÓMEZ CONTRERAS** \\ UNIVERSIDAD NACIONAL DE COLOMBIA
}

Recibido/ Received/ Recebido: 20/07/2013 - Aceptado/ Accepted / Aprovado: 19/03/2014

\begin{abstract}
Resumen
En el presente artículo se presenta una reflexión teórica del concepto de desarrollo, analizando el proceso de eufemización por adjetivo que ha aparecido repetidamente en el discurso desarrollista durante los últimos años, enfatizando en una de sus formas más recientes: el "desarrollo sostenible". Para este propósito se realizó una investigación cualitativa soportada en una revisión documental. Como resultado de la investigación se evidencia que la expresión "desarrollo sostenible" no deja de ser un oxímoron que termina combinando dos conceptos totalmente opuestos: desarrollo en términos de crecimiento económico y sustentabilidad ecológica, supeditando ésta última al crecimiento. Ante este escenario se propone el concepto de "sustentabilidad ambiental" como una alternativa que escapa del imaginario del desarrollo existente y posibilita el bienestar social y el equilibrio ecológico.
\end{abstract}

Palabras clave: Desarrollo, Eufemización, Desarrollo sostenible, Sustentabilidad ambiental.

\section{FROM SUSTAINABLE DEVELOPMENT TO ENVIRONMENTAL SUSTAINABILITY}

\begin{abstract}
This article shows a theoretical reflection on development's concept, analyzing the euphemization process as an adjective that has been repeatedly appearing in the development speech in recent years, emphasizing on one of its most recent forms: "sustainable development". For this purpose, a qualitative research was developed supported on literature reviewing. As a result, the research showed that the term "sustainable development" is nothing else but an oxymoron that at the end combine two completely opposite concepts: development in terms of economic growth and ecological sustainability, subordinating the latter to just growth. In this scenario, it is proposed that the concept of "environmental sustainability" appears as an alternative to avoid the existing development concept but allows social welfare and ecological balance.
\end{abstract}

Keywords: Development, Euphemization, Sustainable Development, Environmental sustainability.

\footnotetext{
El presente artículo se deriva del proceso de revisión bibliográfica realizada en el marco de la investigación "Cultura Organizacional para una gestión ambiental comprometida con la sustentabilidad: Una aproximación teórica”, la cual fue realizada por la autora como tesis en la Maestría de Administración de la Universidad Nacional de Colombia -Sede Bogotá- Facultad de Ciencias Económicas.

** Contadora Pública y Magíster en Administración de la Universidad Nacional de Colombia. Asesora de Proyectos de la Unidad de Emprendimiento e Innovación y Miembro del Grupo de Investigación INTERGES de la Universidad Nacional de Colombia. Correo electrónico: jlgomezc@unal.edu.co
} 


\title{
DO DESENVOLVIMENTO SUSTENTÁVEL À SUSTENTABILIDADE AMBIENTAL
}

\begin{abstract}
Resumo
No presente artigo se apresenta uma reflexão teórica do conceito de desenvolvimento, analisando o processo de eufemismo por adjetivo aparecido repetidamente no discurso desenvolvimentista durante os últimos anos que enfatiza numa de suas formas mais recentes o "desenvolvimento sustentável". Para este propósito se realizou uma pesquisa qualitativa suportada numa revisão documental. Como resultado da pesquisa se evidencia que a expressão "desenvolvimento sustentável" não deixa de ser um oximoro que termina combinando dois conceitos totalmente opostos: desenvolvimento em termos de crescimento econômico e sustentabilidade ecológica, subordinando esta última ao crescimento. Frente a este cenário se propõe o conceito de "sustentabilidade ambiental" como uma alternativa que escapa do imaginário do desenvolvimento existente e possibilita o bemestar social e o equilíbrio ecológico.
\end{abstract}

Palavras chave: Desenvolvimento, Eufemismo, Desenvolvimento sustentável, Sustentabilidade ambiental.

Gómez, J. (2014) Del Desarrollo Sostenible a la Sustentabilidad Ambiental. En: Revista de la Facultad de Ciencias Económicas de la Universidad Militar Nueva Granada. rev.fac.cienc.econ, XXI (1).

JEL: K32, Q56, Q58.

\section{Introducción}

Seis décadas han transcurrido desde aquel 20 de enero de 1949 en el cual el presidente Harry Truman definió por primera vez a los países más pobres como "áreas subdesarrolladas", reduciendo la diversidad de estos países en una sola palabra: subdesarrollados, con lo cual se dio inicio a la era del desarrollo (Sachs, 1996). Cabe señalar que, "cuando ya todos los países quedaron bien atados al único carro del desarrollo, se sustituyó la calificación de países subdesarrollados por la más ambigua y menos peyorativa de países "en vías de desarrollo", presuponiendo que todos estaban, con mejor o peor fortuna, tratando de "desarrollarse", y más recientemente, por la de países "emergentes", presuponiendo que tratan de emerger del pozo ya innombrable del subdesarrollo" (Naredo, 2006, 182).

A este respecto vale la pena anotar que para propósitos de la presente investigación siguiendo a Galeano (2011) se considera que el desarrollo del capitalismo mundial fue el causante del "subdesarrollo" del Tercer Mundo, en la medida que el desarrollo de los países ricos ha generado, genera y seguirá generando la pobreza y la miseria de los países "subdesarrollados".

Así pues, haciendo referencia a los países Latinoamericanos -pero entendiendo que también puede aplicarse para describir la situación del resto de países subdesarrollados, esto es; Asia y África- puede decirse que "nuestra derrota estuvo siempre implícita en la victoria ajena; nuestra riqueza ha generado siempre nuestra pobreza para alimentar la prosperidad de otros: los imperios y sus caporales nativos" (Galeano, 2011, 16). Más aún, la explotación de la gente y el saqueo de los recursos del Tercer Mundo fueron tal vez los factores más importantes que posibilitaron la acumulación originaria y el desarrollo de los Países del Primer Mundo.

Retomando lo correspondiente a la doctrina Truman cabe mencionar que ésta mediante la estrategia del desarrollo pretendía que se produjera una restructuración total de las sociedades menos avanzadas, con el fin de posibilitar la reproducción de las particularidades de las sociedades avanzadas de 
la época -industrialización, un alto grado de urbanización, niveles altos de educación, tecnificación de la agricultura, adopción generalizada de los valores y los principios de la modernidad como son: orientación individual, prosperidad material y progreso económico- en todo el mundo (Escobar, 1996; 1997). Esto debido a que, las sociedades más avanzadas -occidentales/modernas- han sido vistas por años como el ejemplo a seguir por excelencia, y es por ello que conceptos como "avanzar", "progresar", "desarrollarse", entre otros, se encuentran a la orden del día en la agenda de políticos y gobiernos, los cuales buscan de manera exacerbada que sus países logren el tan anhelado desarrollo, pues ven o quieren ver en éste la receta mágica que eliminará los desequilibrios económicos, sociales y ambientales presentes en la actualidad.

Después de 60 años, hay un gran desencanto en tanto que la idea del desarrollo -cimentada sobre el pensamiento occidental moderno, y según la cual el progreso científico y técnico son factores claves e indispensables para mejorar el bienestar de las personas y de la tierra- ha resultado inviable en la medida que: (i) no ha generado mejoras en el bienestar de las personas y de la naturaleza, y (ii) la brecha entre los países desarrollados y subdesarrollados no ha sido cerrada, sino que por el contrario se ha ido incrementando la polarización de la riqueza entre las regiones y entre los individuos (Sachs, 1996; Latouche, 2007). Más aún, "los dos presupuestos fundamentales de la promesa del desarrollo han perdido su validez. Porque la promesa descansaba sobre la creencia, primero, que el desarrollo podía ser universalizado en el espacio, y segundo, que sería durable en el tiempo. En ambos sentidos, sin embargo, el desarrollo ha sido revelado como finito, y es precisamente esta idea la que constituye el dilema que permea muchos debates internacionales desde la Conferencia de Naciones Unidas sobre Ambiente en Estocolmo en 1973" (Sachs, 1996, 21)

Pese a las múltiples críticas existentes en torno al desarrollo y de que en la década de 1990 el desarrollo ya no se consideraba como un proyecto viable en los foros internacionales importantes como el del Fondo Monetario Internacional, el Banco Mundial, etc. Durante los últimos años el desarrollo ha sido reivindicado, de hecho en la década del año 2000 se asistió a una "verdadera resurrección del desarrollo, hasta el punto de que en diciembre de 2001, la OMC le dedicó la Cumbre de Doha (Qatar) y en la primavera de 2002, la ONU, la conferencia de Monterrey (México)" (Latouche, 2007, 15).

A este respecto, vale la pena señalar que si el desarrollo sobrevive aún se debe a la inauguración de la era del desarrollo "en partículas" (Latouche, 2007), al proceso de eufemización por adjetivo, es decir, del creciente uso de adjetivos para acompañar el concepto de desarrollo (social, sostenible, etc.). Sin embargo, al añadirle el adjetivo "humano", "sostenible", "alternativo" a la noción de desarrollo, no se ha cuestionado al desarrollo en sí mismo, a lo mucho se le ha agregado un aspecto "humano", "sostenible", "alternativo" al crecimiento económico, lo cual es inconcebible, en tanto que el desarrollo existente al tener como eje principal el crecimiento económico, inevitablemente engendra injusticia social y detrimento ecológico.

Así las cosas, con el proceso de eufemización por adjetivo se ha intentado cambiar las palabras y no la situación de fondo (Latouche, 2007). Ante el escenario mencionado, es importante abordar más a fondo en qué condiciones surgió el desarrollo, cómo ha sido su proceso de evolución, qué implicaciones tiene el uso de dicho concepto, cuáles han sido sus múltiples mutaciones, alternativas de y al desarrollo, entre otros temas. Por lo cual, en el presente artículo se procederá a abordar lo referente al surgimiento del desarrollo, sus múltiples mutaciones a lo largo del tiempo, y teniendo en cuenta que "los problemas del medio ambiente son los problemas del desarrollo, los problemas de un desarrollo desigual para las sociedades humanas y nocivo para los sistemas naturales" (Guimares \& Barcena, 2002, 28), se hará énfasis en el desarrollo sostenible y la sustentabilidad ambiental como alternativa al desarrollo.

Para lo cual el documento se divide en 3 secciones. En la primera sección se realiza una revisión del surgimiento del discurso del desarrollo, de sus implicaciones y las críticas existentes al mismo. En segundo lugar, se aborda lo correspondiente al proceso de eufemización por adjetivo que ha pululado en el discur- 
so desarrollista durante los últimos años, enfatizando en la problemática ambiental y en el surgimiento del desarrollo sostenible. En el tercer apartado se trata más a fondo el concepto de desarrollo sostenible, se analizan sus diferentes corrientes, y se propone el concepto de "sustentabilidad ambiental" como una alternativa que escapa del imaginario del desarrollo existente y posibilita el bienestar social y el equilibrio ecológico.

Se realizó una investigación cualitativa de tipo analítica soportada en una revisión documental de 25 documentos (artículos y libros) de autores relevantes en el debate de ambiente y desarrollo haciendo especial énfasis en los aportes de Eschenhagen (2006; 2001), Escobar (1999; 1997; 1996), Latouche (2007), Leff (2008; 2004; 2000), Naredo, (2006; 1999) y Sachs (1996).

\section{Una aproximación crítica al concepto del desarrollo}

Dentro de los principales factores acaecidos entre 1945 y 1955 que dieron forma al discurso del desarrollo se encuentran: (i) las crecientes luchas por la independencia nacional de Asia y África, y el creciente nacionalismo latinoamericano, a inicios de la década de 1950, (ii) la nueva forma de ver al Tercer Mundo como un área estratégica por el acceso a materias primas, que llevó a que se buscara su inserción en la estructura económica y política mundial a partir de la Segunda Guerra Mundial, (iii) la guerra fría, (iv) la necesidad de nuevos mercados, (v) el temor al comunismo, (vi) la superpoblación, y (vii) la fe en la ciencia y la tecnología (Escobar, 1996). A continuación en la Tabla 1 se procede a explicar cada uno de estos factores con mayor profundidad.

Adicionalmente, el aspecto quizás más importante que dio forma al discurso del desarrollo en este periodo (1945-1955) fue el "descubrimiento" de la pobreza masiva que reinaba en Asia, África y Latinoamérica, y el surgimiento de la categoría de áreas o países "subdesarrollados", circunstancia que tuvo lugar en los primeros años siguientes a la Segunda
Tabla 1. Los principales factores que dieron forma al discurso del desarrollo1

\begin{tabular}{|c|c|}
\hline $\begin{array}{l}\text { Principales } \\
\text { Factores }\end{array}$ & Contextualización \\
\hline $\begin{array}{l}\text { Luchas por la in- } \\
\text { dependencia en } \\
\text { Asia y África y } \\
\text { nacionalismo lati- } \\
\text { noamericano }\end{array}$ & $\begin{array}{l}\text { Para que los países de Primer Mundo pudieran } \\
\text { seguir disfrutando de control sobre los países de } \\
\text { Tercer Mundo se requería un nuevo sistema de co- } \\
\text { lonización (el desarrollo), puesto que "los viejos } \\
\text { sistemas coloniales de explotación y control se } \\
\text { hicieron insostenibles (demandando) una reorgani- } \\
\text { zación de la estructura del poder mundial" (Esco- } \\
\text { bar,1996, 73) }\end{array}$ \\
\hline $\begin{array}{l}\text { Visualización del } \\
\text { Tercer Mundo } \\
\text { como un área } \\
\text { estratégica, la ne- } \\
\text { cesidad de nuevos } \\
\text { mercados }\end{array}$ & $\begin{array}{l}\text { La economía norteamericana buscaba expandir sus } \\
\text { mercados a nivel mundial, para lo cual necesitaba } \\
\text { acceder a materias primas de bajo costo para poder } \\
\text { cubrir la capacidad de sus industrias. Dichas mate- } \\
\text { rias se encontraban en los países subdesarrollados. }\end{array}$ \\
\hline La guerra fría & $\begin{array}{l}\text { Con la guerra fría se asistió al surgimiento de un } \\
\text { "nuevo orden mundial" y a una reconfiguración del } \\
\text { poder. Al mismo tiempo que, el Tercer Mundo se } \\
\text { convirtió en "la arena más importante de confronta- } \\
\text { ción (como lo indican Somalia, la guerra del golfo, } \\
\text { el bombardeo de Libia y las invasiones de Grenada } \\
\text { y Panamá)" (Escobar, 1996, 76). }\end{array}$ \\
\hline $\begin{array}{l}\text { El temor al comu- } \\
\text { nismo }\end{array}$ & $\begin{array}{l}\text { "En los años cincuenta se aceptaba comúnmente } \\
\text { que si los países pobres no eran rescatados de } \\
\text { su pobreza, sucumbirían al comunismo" (Esco- } \\
\text { bar,1996, 76), por lo cual para evitar que los paí- } \\
\text { ses tercermundistas cayeran en el comunismo era } \\
\text { indispensable recatarlos de la pobreza en la cual } \\
\text { vivían. }\end{array}$ \\
\hline La superpoblación & $\begin{array}{l}\text { "Como lo sugería la experiencia de Occidente, se } \\
\text { esperaba que las tasas de crecimiento comenzaran } \\
\text { a caer a medida que los países se desarrollaran; } \\
\text { pero, como advirtieron muchos, los países pobres } \\
\text { no podían esperar hasta que este proceso ocurrie- } \\
\text { ra y debían agilizar la reducción de la fertilidad por } \\
\text { medios más directos" (Escobar,1996, } 77 \text { ). }\end{array}$ \\
\hline $\begin{array}{l}\text { La fe en la ciencia } \\
\text { y la tecnología }\end{array}$ & $\begin{array}{l}\text { En el siglo XIX la ciencia y la tecnología se convir- } \\
\text { tieron en abanderadas por excelencia, se considera- } \\
\text { ba que el desarrollo de un país dependía más de la } \\
\text { asistencia técnica que del capital, y de esta forma el } \\
\text { concepto de "transferencia de tecnología" se con- } \\
\text { virtió en un componente crucial en los proyectos } \\
\text { de desarrollo }\end{array}$ \\
\hline
\end{tabular}

1 Fuente: Elaboración propia con base en Escobar (1996). 
Guerra Mundial y que hizo que "el discurso bélico se (desplazara) al campo social y hacia un nuevo territorio geográfico: el Tercer Mundo" (Escobar, 1996, 51).

Así pues, los problemas crónicos de "pobreza" de los países "tercermundistas" empezaron a ocupar un lugar de suma relevancia en el escenario internacional, en el sentido que se consideraba que los países ricos y los pobres se encontraban inevitablemente ligados y por tanto la prosperidad del Primer Mundo no podría perdurar si el Tercer Mundo continuaba viviendo en condiciones de "pobreza" y malestar social. Por lo cual, se llegó a la conclusión de que se debía actuar antes de que los niveles de pobreza alcanzaran niveles más altos (Escobar, 1996)

Ahora bien, como el nivel de desarrollo del país en este periodo se medía únicamente con el Producto Nacional Bruto (PNB) o con el ingreso per cápita cuando se divide por la población total de un país (Rogers, 1976), la solución a la pobreza que vivían los países "subdesarrollados" era trabajar en el aumento del PNB. Por lo cual, para combatir la "pobreza" de los países "subdesarrollados", Truman en su discurso de posesión como presidente de Estados Unidos en 1949, lanzó el Programa Point IV, el cual comprendía la inserción de tecnología moderna y capital en los países del Tercer Mundo; al mismo tiempo que comunicó al mundo entero su concepción de "trato justo", haciendo un llamado a Estados Unidos y al resto del países ricos a "ayudar" a los países "pobres", es decir, "subdesarrollados" a resolver sus problemas ${ }^{2}$. Así pues, en este periodo se destacó el crecimiento económico a través de la industrialización como la clave del desarrollo, e igualmente en el corazón de la industrialización se proponían a la tecnología y al capital como la solución a los problemas de pobreza del tercer mundo. Esta idea de desarrollo surgió de la experiencia de la Revolución Industrial en Europa Occidental y América del Norte (Rogers, 1976)
El desarrollo ${ }^{3}$ como proyecto fue formulado inicialmente en Estados Unidos y Europa durante los años posteriores al fin de la Segunda Guerra Mundial, y a partir de entonces fue aceptado por los gobernantes del Tercer Mundo (Escobar, 1996; Latouche, 2007). No obstante, la introducción del proyecto desarrollista en los países tercermundistas resulta contracultura en tanto que "se universaliza y se impone la necesidad del progreso y desarrollo a nivel global, sin tener en cuenta todos los procesos históricos, sociales, políticos, económicos por los cuales tuvo que pasar la propia Europa para llegar a tales puntos de desarrollo. Se partía del hecho de que todo el mundo puede y debe llegar al mismo punto, implantando simplemente ciertos tipos de políticas científicas, económicas y sociales" (Eschenhagen, 2001, 112). A este respecto vale la pena señalar que:

- El Programa Point IV proporcionaba un tratamiento muy diferente a los países "subdesarrollados" del que fue recibido por Europa con el Plan Marshall. Más aún, con el Programa de Truman no se proveía una colaboración verdadera a los países "subdesarrollados", sino que se creaba un "clima adecuado" para expandir el desarrollo capitalista, para controlar el nacionalismo que se estaba instaurando en los países de Tercer Mundo, y para mantener bajo control a la izquierda, a la clase trabajadora y al campesinado (Escobar, 1996). Más aún, el mensaje cifrado del Programa Point IV era que para resolver sus problemas los países "subdesarrollados" deberían privilegiar el capital privado y foráneo, y no esperar ayudas económicas extraordinarias como sucedió con el Plan Marshall.

- Los parámetros para definir la pobreza de los países se tornaron netamente económicos, de modo que el ingreso anual per cápita se convirtió en el indicador por excelencia para catalogar a un país como rico o pobre. De modo que, a partir de aquella época se empezó a defender la idea de que si el ingreso anual per cápita señalaba la existencia de pobres en

2 Los componentes más importantes para resolver dichos problemas según Truman eran el capital, la ciencia y la tecnología, pues con la introducción de estos tres elementos los países menos avanzados tendrían la oportunidad de desarrollarse.

3 El desarrollo según Escobar (1996) debe ser visto como un "régimen de representación, como una "invención" que resultó de la historia de la posguerra y que, desde sus inicios, moldeó ineluctablemente toda posible concepción de la realidad y la acción social de los países que desde entonces se conocen como subdesarrollados" (Escobar, 1996, 14). 
un país, entonces la solución de la pobreza era el desarrollo en términos de crecimiento económico, en tanto que con este se aumentaría el ingreso anual per cápita, y así fue como se instauró al crecimiento económico como la solución al problema de pobreza del Tercer Mundo, más aún se proclamó al desarrollo económico como la salvación ${ }^{4}$ de los países pobres ${ }^{5}$ (Escobar, 1996)

Así las cosas, "los pobres aparecieron cada vez más como un problema social que requería nuevas formas de intervención en la sociedad... (y) el tratamiento de la pobreza permitió a la sociedad conquistar nuevos territorios" (Escobar, 1996, 53), mediante la intervención en aspectos como salud, educación, vivienda, ahorro, etc. Ahora bien, dichas intervenciones en el Tercer Mundo significaron la invención de un campo denominado como "lo social", el cual como campo de conocimiento e intervención "cobró importancia en el siglo XIX, culminando en el siglo XX con la consolidación del Estado benefactor y el conjunto de técnicas agrupadas bajo el nombre de trabajo social. (Pero) no sólo la pobreza, sino también la salud, la educación, la higiene, el empleo y la baja calidad de vida en pueblos y ciudades se convirtieron en problemas sociales" (Escobar, 1996, 54)

Por otro lado, cabe mencionar que desde sus inicios el proyecto del desarrollo contenía una propuesta inaudita, se planteaba una transformación cultural total de tres continentes (Asia, África y Latinoamérica) en consonancia con los dictados del Primer Mundo, lo cual significaba la adopción de la prosperidad material y el progreso económico como objetivos deseables a perseguir. Ahora bien, para posibilitar el progreso económico se planteó una reestructuración total de las "áreas subdesarrolladas", dicha reestructuración era una propuesta sumamente etnocéntrica, descabellada, egoísta o "ingenua" en el mejor de los casos, en tanto que implicaba la erradicación de las filosofías ancestrales y la desintegración de las anteriores instituciones sociales principalmente (Escobar, 1996; Latouche, 2007). Así pues, lo que en últimas se buscaba era generar las condiciones que garantizaran la reproducción en todo el globo de "los rasgos característicos de las sociedades avanzadas de la época: altos niveles de industrialización y urbanización, tecnificación de la agricultura, rápido crecimiento de la producción material y los niveles de vida, y adopción generalizada de la educación y los valores culturales modernos" (Escobar, 1996, 20).

En este orden de ideas, puede decirse que el discurso $^{6}$ del desarrollo ha sido resultado de un proceso histórico y hunde sus raíces en la creencia de que el desarrollo es la salvación del tercer mundo ante los problemas sociales de pobreza y atraso que les atañe, y que pese a ser una estrategia "expresada en términos de metas humanitarias y de la preservación de la libertad (...) buscaba un nuevo control de los países y de sus recursos" (Escobar, 1996, 59). De tal modo, el desarrollo económico no fue más que el nuevo nombre de la política hegemónica americana, para "permitir que los Estados Unidos se apoderaran de los mercados de los ex imperios coloniales europeos, y evitar así que los nuevos estados independientes cayeran en manos soviéticas. (A este respecto, cabe mencionar que antes del desarrollo) el nombre más antiguo de la occidentalización era simplemente la colonización y el viejo imperialismo. (Así pues, el desarrollo) no ha significado más que la continuación de la colonización por otros medios" (Latouche, 2007, 19-20).

El desarrollo como mito y el desarrollo como realidad histórica son dos cosas totalmente diferentes. La visión mítica del desarrollo implicaba la realización de los deseos y ambiciones de todos, de manera que el desarrollo defendido bajo esta visión es como el mirlo blanco en tanto que nadie lo ha visto

4 Para lograr dicha tarea de salvación eran consideradas como herramientas indispensables; la tecnología, la planeación, la ciencia y la colaboración de organizaciones internacionales.

5 Estas herramientas habían sido creadas y probadas en el Primer Mundo y eran consideradas "eficaces", "deseables", "neutrales", y "universalmente aplicables" (Escobar,1996).

6 El concepto discurso se toma siguiendo a Foucault, quien habló sobre el discurso de la modernidad. El discurso puede ser visto como un lenguaje del poder, el cual define y dispone, visibiliza e invisibiliza situaciones o cosas. 
jamás. De otro lado, el desarrollo como realidad histórica independientemente del adjetivo que le acompañe ha traído, trae y siempre traerá subdesarrollo, creciente pobreza, hambruna, desnutrición, miseria sin límites, violencia, explotación y opresión (Latouche, 2007), ciertamente "basta una mirada superficial a los paisajes biofísicos, económicos y culturales de la mayor parte del Tercer Mundo para darse cuenta de que el desarrollo está en crisis, y que la violencia, pobreza y deterioro social y ambiental crecientes son el resultado de cincuenta años de recetas de crecimiento económico, "ajustes estructurales", macroproyectos sin evaluación de impacto, endeudamiento perpetuo, y marginamiento de la mayoría de la población de los procesos de pensamiento y decisión sobre la práctica social" (Escobar, 1996, 13). De tal modo, lo que finalmente se ha logrado con el desarrollo es multiplicar los problemas del Tercer Mundo e incrementar la heteronomía en menoscabo de la autonomía de las sociedades (Escobar, 1996; Latouche, 2007).

\section{En suma, se puede definir al desarrollo}

\begin{abstract}
"Como una empresa que pretende transformar en mercancía la relación de los hombres entre ellos y con la naturaleza. (Una empresa que) trata de explotar, de ponerle un valor, de sacar ganancias de los recursos naturales y humanos. Una empresa agresiva con la naturaleza y con los pueblos, que es, de igual modo que la colonización que la precede y la globalización que la sigue, una obra a la vez económica y militar de dominación y conquista. (De ahí que) lo queramos o no, no podemos hacer que el desarrollo sea diferente de lo que ha sido (esto es) la occidentalización del mundo" (Latouche, 2007, 22).
\end{abstract}

Por tanto, sin importar cuál sea el adjetivo que acompañe el término desarrollo, éste no tiene ni tendrá un lenguaje diferente al de crecimiento económico y acumulación de capital, los cuales conllevan competencia despiadada, aumento de la desigualdad, y saqueo incontrolado de la naturaleza (Escobar, 1996; Latouche, 2007).
Ahora bien, después de haber realizado una revisión del surgimiento del discurso del desarrollo, de sus implicaciones y las críticas existentes al mismo, en el siguiente apartado se abordará lo correspondiente al proceso de eufemización por adjetivo que ha pululado en el discurso desarrollista durante los últimos años. Haciendo la salvedad de que no es motivo de la presente investigación abordar en profundidad cada una de las mutaciones del desarrollo, sino que solo se profundizará en el desarrollo sostenible.

\section{La era de los desarrollos "en partícula"}

A pesar de que, a inicios de la década de 1950 la idea de transformar a Asia, África y Latinoamérica conforme a los mandatos de los países del Primer Mundo ya se encontraba inserta y predominaba en los círculos de poder, y de que a finales de la década de 1970 el tipo de desarrollo que debía insertarse en los países del tercer mundo para resolver los problemas sociales de aquellas regiones era la principal preocupación para teóricos y políticos. También se vislumbraba una corriente que rechazaba la idea de un desarrollo soportado sobre las estrategias capitalistas de la época, proponiendo en cambio otros tipos de desarrollos como el "socialista", el "participativo" o simplemente "otro" desarrollo (Escobar, 1996).

El problema de fondo de ese tipo de propuestas "alternativas", es que no cuestionan al desarrollo medido en términos de crecimiento económico en sí mismo, lo que hacen es proponer modificaciones o mejoras al desarrollo existente, sin que ello implique salirse del ideario del crecimiento económico. Lo cual es resultado de la colonización de la realidad por el discurso del desarrollo. De manera que, quienes se encontraban inconformes con el statu quo existente se veían obligados a luchar dentro de ese mismo espacio discursivo con la esperanza de que por el camino se lograría construir una realidad distinta, situación con la cual se inauguró la era de los desarrollos "en partícula" (Escobar, 1996; Latouche, 2007).

Dicha era hace referencia al proceso de eufemización con el cual se optó por añadirle un adjetivo al 
concepto de desarrollo, sin que ello implicara cuestionar el crecimiento económico como objetivo a perseguir, en últimas lo único que se hizo fue agregar un adjetivo positivo al crecimiento económico, y así fue como surgieron desarrollos "participativos", "sociales", "sostenibles", "sustentables", "alternativos", "comunitarios", entre otras denominaciones. Sin embargo, los adjetivos "social", "sostenible", etc., no son más que mascaras o vestidos nuevos del desarrollo económico. Ante este panorama resulta de suma relevancia detenerse a examinar algunas de las máscaras del desarrollo, por ello a continuación en la Tabla 2 se abordara de manera general las más recientes y persistentes mutaciones del desarrollo como son el desarrollo social, el desarrollo humano, el desarrollo local y el desarrollo sostenible.

Tabla 2. Diferentes tipos de desarrollo ${ }^{7}$

\begin{tabular}{|c|c|}
\hline Tipo de desarrollo & Descripción \\
\hline Social & $\begin{array}{l}\text { Con el desarrollo social se intentó añadirle un } \\
\text { aspecto social al crecimiento económico, más en } \\
\text { ningún momento se pone en cuestión el desarro- } \\
\text { llo. De tal modo, se habla de un nuevo paradigma } \\
\text { de desarrollo pero sin tocar el tótem del libre in- } \\
\text { tercambio mundial, y al no tocar dicho tótem se } \\
\text { siguen produciendo y profundizando la dinámica } \\
\text { de uniformización, occidentalización, descultura- } \\
\text { ción y exclusión, en detrimento de la diversidad, } \\
\text { la igualdad y el bienestar de los países del Tercer } \\
\text { Mundo. }\end{array}$ \\
\hline Humano & $\begin{array}{l}\text { El desarrollo humano surge ante la insuficiencia } \\
\text { del Producto Nacional Bruto (PNB) per cápita para } \\
\text { medir el desarrollo en términos más amplios al } \\
\text { crecimiento económico, de ahí que el desarrollo } \\
\text { humano es de alguna forma el complemento esta- } \\
\text { dístico del desarrollo social. Este tipo de desarro- } \\
\text { llo se mide a través de un índice de Desarrollo Hu- } \\
\text { mano propuesto por el Programa de las Naciones } \\
\text { Unidas para el Desarrollo (PNUD), dicho índice } \\
\text { representa un avance en tanto que tiene en cuenta } \\
\text { dimensiones sociales como la salud, la educa- } \\
\text { ción, entre otras. No obstante, cabe mencionar } \\
\text { que aún bajo esta perspectiva el desarrollo queda } \\
\text { reducido a términos económicos, pues se sigue } \\
\text { midiendo el nivel de vida atendiendo al número de } \\
\text { dólares per cápita. }\end{array}$ \\
\hline
\end{tabular}

\begin{tabular}{|c|l|}
\hline \multirow{7}{*}{ El desarrollo local como tal surgió para enmas- } \\
carar la transformación del territorio8 y es un \\
concepto contradictorio en tanto que "el desa- \\
rrollo es la consecuencia de un proceso econó- \\
mico que no es ni local, ni regional, ni tampoco \\
nacional (incluso si el Estado-Nación ha sido el \\
actor privilegiado), sino fundamentalmente mun- \\
dial (y sobre todo en la época actual)" (Latouche, \\
2007, 36). Más aún, resulta incorrecto confundir \\
crecimiento localizado (crecimiento de los siste- \\
mas locales como respuesta a lógicas globales) \\
y desarrollo local. Ahora bien, una de las tantas \\
paradojas del desarrollo local es la adopción de \\
un "glocalismo", mediante el cual se ponen a los \\
territorios en competencia, invitándolos a ofrecer \\
condiciones cada vez más favorables a las em- \\
presas multinacionales en términos de ventajas \\
fiscales, mano de obra barata, desregulación \\
ambiental, etc.
\end{tabular}

Después de haber descrito de manera general las principales mutaciones del desarrollo, a continuación se procederá a abordar lo respectivo a la problemática ambiental y al desarrollo sostenible o sustentable. Para lo cual en primer lugar se hará una aproximación a la problemática ambiental y como a raíz de ella surgió el concepto de desarrollo sostenible.

\subsection{Una aproximación a la problemática ambiental: ¿Desarrollo sostenible? o ¿Sostenibilidad del desarrollo?}

Hacia finales de 1960 e inicios de 1970 la crisis ambiental se incorporó en la arena política, debido en parte a un conjunto de informes científicos que aler-

7 Fuente: Elaboración propia a partir de Latouche (2007) y Escobar (1996).

8 Bajo este tipo de desarrollo "estamos frente a unos territorios sin poder que están a merced de un poder sin territorios" (Latouche, 2007, 37), en la medida que este tipo de desarrollo posibilita una gestión a distancia, descentralizada y unificada. 
taron sobre el agotamiento de los recursos naturales, el riesgo ambiental creado por la misma humanidad, la extinción continua de especies, etc., que pusieron en evidencia los grandes problemas ambientales ${ }^{9}$ de la época (Pierri, 2005). Dicha crisis ambiental tuvo sus orígenes tanto en el incremento de la extracción de recursos naturales, como en la progresiva generación de residuos inherente al proceso productivo (Ilustración 1). De tal modo, la preocupación por el ambiente por parte de políticos, científicos, académicos y grupos ecologistas se debió principalmente a la percepción sobre el agotamiento de los recursos naturales y al deterioro progresivo de la naturaleza resultante de los desechos del proceso productivo (Arroyo, Camarero \& Vásquez, 1997)

\section{Ilustración 1. Ciclo productivo ${ }^{10}$}

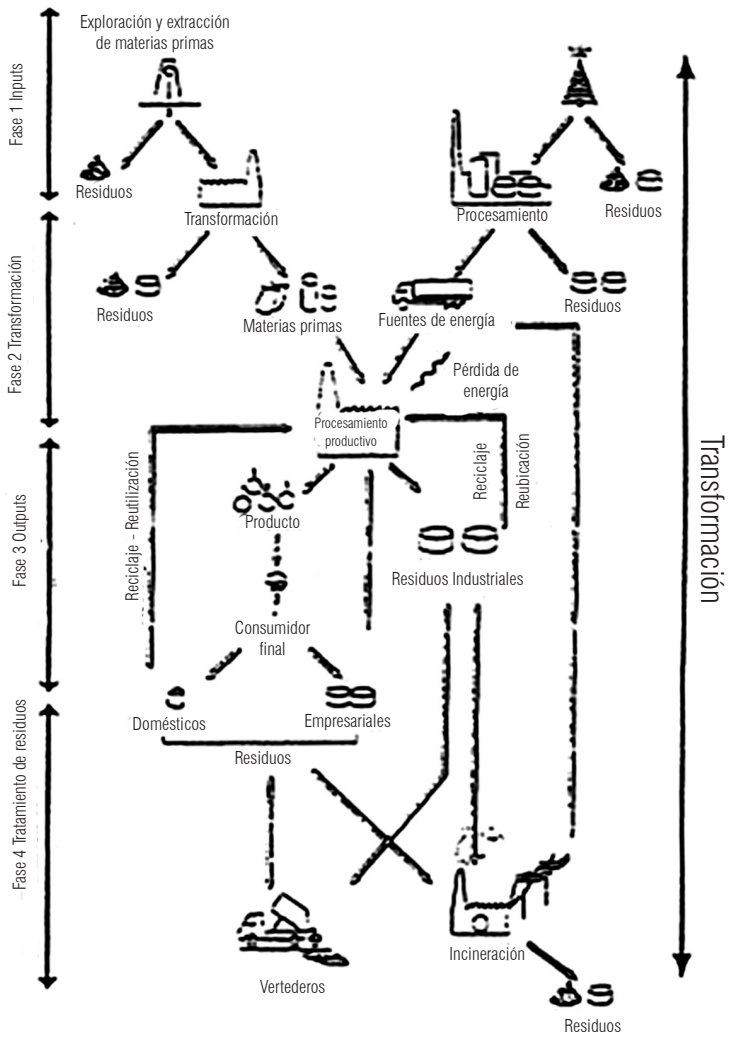

En la Ilustración 1 se aprecia el proceso de transformación del ciclo de vida de un producto, desde la extracción de materias primas necesarias para su fabricación, hasta su transformación en residuo después de haber sido consumido. Como se puede observar los ciclos humanos a diferencia de los ciclos naturales, tienen una mínima capacidad de reciclaje y pueden resultar nocivos para el ambiente (Ludevid, 2000).

En suma, ante la percepción del agotamiento de los recursos no renovables y del deterioro creciente del medio natural como resultado de los desechos de la civilización industrial, el ambiente se convirtió en objeto de preocupación para los políticos, los científicos y la comunidad en general (Arroyo, Camarero \& Vásquez, 1997). Motivo por el cual, se redactaron diferentes documentos (Informe del Club de Roma, Informe Brundtland, entre otros) en los cuales se manifestó la importancia internacional del ambiente, y se celebraron varias conferencias ambientales mundiales por parte de la Organización de las Naciones Unidas -ONU-. Dentro de las más importantes de dichas conferencias se encuentran las celebradas en Estocolmo, Rio de Janeiro y Johannesburgo en los años de 1972, 1992 y 2002 correspondientemente. Adicional a las conferencias mencionadas, a partir de 1970 la creciente conciencia ambiental se profundizó debido a una serie de acontecimientos que se relacionarán a continuación en la Tabla 3.

Así pues, en 1972 es publicado "Los límites al crecimiento" también conocido como el Informe del Club de Roma, el cual es uno de los primeros documentos en los cuales se manifiesta la preocupación por la problemática ambiental global, indicando que "un crecimiento económico continuado llevaría a un colapso, sea por acumulación de la contaminación o por extinción de recursos. (Y que) la producción industrial per cápita terminaría cayendo así como la disponibilidad de alimentos y recursos, de donde la

\footnotetext{
Vale la pena señalar que la problemática ambiental pese a que se presente bajo diversas formas (efecto invernadero, cambio climático, destrucción de la capa de ozono, perdida de la biodiversidad, contaminación del agua, del aire y de la tierra, etc.), y afecte a diversas poblaciones, es común y global. Por lo cual, las soluciones de la problemática tendrán que ser también globales, es decir, sin diferencias de intereses o naciones (Arroyo, Camarero \& Vásquez, 1997)

10 Fuente: Ludevid $(2000,52)$.
} 
población mundial disminuiría por un aumento de la tasa de mortalidad" (Gudynas, 2002, 46). Más aún, la principal conclusión de este informe es que "si las tendencias continuaban, el sistema global se sobrecargaría y colapsaría para el año 2000. Para evitarlo, tanto el crecimiento demográfico como el económico tendrían que detenerse" (Meadows \& Meadows, 1972; Citado en Sabogal \& Hurtado, 2009, 204). Pese a que las predicciones planteadas en el documento no se cumplieron en el grado señalado, la importancia de este documento radica en que por primera vez se hizo público el concepto de límites externos, manifestando que el desarrollo económico se encuentra condicionado por los recursos naturales (Sabogal \& Hurtado, 2009).

Tabla 3. Principales sucesos en relación a lo ambiental11

\begin{tabular}{|c|c|}
\hline \multicolumn{2}{|c|}{$\begin{array}{l}\text { Cronología de los principales sucesos y conferencias internaciona- } \\
\text { les relacionados con la conciencia ecológica de la población }\end{array}$} \\
\hline 1948 & $\begin{array}{l}\text { Creación de la International Union for the Conservation of } \mathrm{Na}- \\
\text { ture (IUCN) }\end{array}$ \\
\hline 1955 & $\begin{array}{l}\text { Simposio sobre Man's role in changing the face of the Earth, } \\
\text { Priceton (USA) }\end{array}$ \\
\hline $\begin{array}{l}1960- \\
1970\end{array}$ & $\begin{array}{l}\text { Publicación de los libros de impacto como los de R. Carson, } \\
\text { Silent Spring (1963), K. Boulding, The Economics of the Co- } \\
\text { ming Spaceship Earth (1966), o Ehrlich, The Population Bomb } \\
\text { (1968) }\end{array}$ \\
\hline \multirow{2}{*}{1971} & $\begin{array}{l}\text { Publicación de I Informe Meadows, The limits of the Growth, } \\
\text { Club de Roma }\end{array}$ \\
\hline & $\begin{array}{l}\text { Creación del Programa Man and Biosphere (MAB) de la } \\
\text { UNESCO }\end{array}$ \\
\hline \multirow{2}{*}{1972} & $\begin{array}{l}\text { Conferencia de Naciones Unidas sobre El Medio Humano, Es- } \\
\text { tocolmo }\end{array}$ \\
\hline & $\begin{array}{l}\text { Creación del Programa de Naciones Unidas sobre Medio Am- } \\
\text { biente (PNUMA) }\end{array}$ \\
\hline 1973 & Primera "crisis energética" \\
\hline 1976 & $\begin{array}{l}\text { Primera Conferencia de Naciones Unidas sobre Asentamientos } \\
\text { Humanos (Hábitat I), Vancouver }\end{array}$ \\
\hline 1979 & Segunda "Crisis Energética" \\
\hline $\begin{array}{l}1970- \\
1980\end{array}$ & $\begin{array}{l}\text { Publicación de numerosos libros de impacto como: H.T. Odum, } \\
\text { Environment, Power and Society (1971), B. Commoner, The } \\
\text { Closing Circle (1972), E.F. Schumacher, Small is Beautiful } \\
\text { (1973), H.T. y E.C. Odum, Energy Basis for Man and Nature } \\
\text { (1976), A. Lovins, Soft Energy Paths (1977), B. Commoner, The } \\
\text { Poverty of Power (1979), G.E. Barney (dir.)(1981). The Global } \\
\text { 2000. Report to the president }\end{array}$ \\
\hline
\end{tabular}

11 Fuente: Naredo $(2006,21)$.

\begin{tabular}{|c|c|}
\hline $\begin{array}{l}1980- \\
2003\end{array}$ & $\begin{array}{l}\text { Abaratamiento del petróleo y de las materias primas en general } \\
\text { Decaen las publicaciones sobre el manejo de la energía y los } \\
\text { materiales en la civilización industrial y aumenta la literatura } \\
\text { sobre instrumentos económicos para la gestión de residuos y } \\
\text { valoración de externalidades a fin de incluir los temas ambien- } \\
\text { tales en el razonamiento económico estándar }\end{array}$ \\
\hline 1987 & $\begin{array}{l}\text { Publicación del Informe Brundtland de la Comisión Mundial de } \\
\text { Medio Ambiente y del Desarrollo: Our Common Future }\end{array}$ \\
\hline & Final de la "guerra fría" \\
\hline 1989 & $\begin{array}{l}\text { Publicación del II Informe Meadows del Club de Roma, Beyono } \\
\text { the Limits. }\end{array}$ \\
\hline 1992 & $\begin{array}{l}\text { Conferencia de las Naciones Unidas sobre Medio Ambiente } \\
\text { Río de Janeiro. Tratado de Maastricht y V Programa de Acción } \\
\text { sobre Medio Ambiente de la Unión Europea (UE) }\end{array}$ \\
\hline 1993 & $\begin{array}{l}\text { Publicación del Libro Blanco sobre crecimiento, productividad } \\
\text { y empleo, de la UE }\end{array}$ \\
\hline & Creación del Proyecto Ciudades Europeas Sostenibles \\
\hline 1994 & Aparecen las Agendas de Desarrollo Local \\
\hline 1995 & $\begin{array}{l}\text { Publicación del Libro Verde sobre el medio ambiente urbano de } \\
\text { la Comisión Europea }\end{array}$ \\
\hline 1996 & $\begin{array}{l}\text { Segunda Conferencia de Naciones Unidas sobre Asentamientos } \\
\text { Humanos (Hábitat II), Estambul }\end{array}$ \\
\hline 1998 & $\begin{array}{l}\text { Conferencia de Naciones Unidas sobre el Cambio Climático } \\
\text { Kyoto }\end{array}$ \\
\hline 2002 & $\begin{array}{l}\text { Conferencia de Naciones Unidas sobre Desarrollo Sostenible } \\
\text { Johannesburgo }\end{array}$ \\
\hline
\end{tabular}

Ahora bien, cuando se puso en tela de juicio el crecimiento económico como objetivo a perseguir con la publicación del Primer Informe del Club de Roma "los límites del crecimiento", Ignacy Sachs propuso el concepto "eco-desarrollo" para intentar conciliar el aumento de la producción con el respeto por la naturaleza. En cierto modo, con las estrategias del eco-desarrollo se buscaba promover otros tipos de desarrollo que se edificaran atendiendo a las condiciones y las potencialidades de la naturaleza, y al uso prudente de los recursos. En este sentido se llegó a concebir que el sistema económico se encontraba inmerso dentro de un sistema más amplio que lo contiene y lo sustenta, esto es el sistema físicobiológico, y por tanto la economía debía considerar las leyes de la termodinámica. Más aún, las estrategias ecodesarrollistas abogaban por la implantación de nuevos modos de producción y estilos de vida, los cuales debían adaptarse tanto a las condiciones y potencialidades ecológicas como a las diversidades 
étnicas y a la autoconfianza de cada región para que se produjera una gestión participativa de los recursos (Leff, 2000).

En suma, el concepto de eco-desarrollo propuesto por Sachs subrayaba la idea de "aprovechar los recursos naturales que son propios de cada bio-región (y no imponer estrategias de producción inadecuadas para cada contexto ecológico), con el objetivo de atender la satisfacción de las necesidades de las poblaciones locales, pero respetando las generaciones futuras (prohibiendo el uso depredador y mitigando el agotamiento de recursos acotados)" (Gudynas, 2002, 46)

Pese a que el uso de dicho término se expandió dentro de los círculos internacionales relacionados con el ambiente y el desarrollo, ésta situación no duro mucho tiempo, pues antes de que las estrategias del eco-desarrollo consiguieran "vencer las barreras de la gestión sectorizada del desarrollo, revertir los procesos de planificación centralizada y penetrar en los dominios del conocimiento establecido, las propias estrategias de resistencia al cambio del orden económico fueron disolviendo el potencial crítico y transformador de las prácticas del eco-desarrollo" (Leff, 2000, 19), lo cual se vio materializado en 1974 cuando en un seminario promovido por las Naciones Unidas que tuvo lugar cerca de Cuernavaca México, "Echeverría, suscribió y presentó a la prensa las resoluciones de Cocoyoc, que hacían suyo el término "eco-desarrollo". (Y) unos días más tarde, según recuerda Sachs en una reciente entrevista, Henry Kissinger manifestó, como jefe de la diplomacia norteamericana, su desaprobación del texto en un telegrama enviado al presidente del Programa de las Naciones Unidas para el Medio Ambiente: (diciendo que) había que retocar el vocabulario (quedando vetado en dichos foros) el término "eco-desarrollo"" (Naredo, 1999, 58) .

A partir de entonces surgió la necesidad de buscar un término que fuera capaz de "ecologizar la economía”, y con el cual se eliminará la contradicción existente entre crecimiento económico y conservación de la naturaleza, de esta manera entra en desuso el concepto de eco-desarrollo, mientras es reemplazado por el de Desarrollo Sostenible (Leff, 2000). Cabe mencionar que, más adelante se abordará más a fondo lo relativo al Desarrollo Sostenible, por ahora se proseguirá con el recuento histórico de la problemática ambiental que se venía realizando.

Por lo que sigue, en ese mismo año (1972) poco tiempo después de la publicación del Informe del Club de Roma e influenciada por este, se realizó la Conferencia de las Naciones Unidas sobre el Medio Humano en Estocolmo, en esta conferencia se sentaron las bases para una política ambiental y una legislación internacional sobre el ambiente. Así mismo, se reconoció la relación que existe entre la destrucción ambiental y el crecimiento económico, señalando que la problemática ambiental es consecuencia de un crecimiento económico mal planificado. Por otro lado, dentro de los resultados prácticos de la conferencia se encuentran: a) la Declaración del 5 de Junio como el Día Mundial de la Tierra, y b) la creación del Programa de las Naciones Unidas para el Medio Ambiente -PNUMA-. Vale la pena señalar que en esta conferencia no se realizan críticas profundas al desarrollo ${ }^{12}$, sino que se propone la planificación del desarrollo para evitar los problemas ambientales (Eschenhagen, 2006).

De tal forma, en Estocolmo se manifiesta que es importante equilibrar los procesos de desarrollo económico con la protección ambiental. No obstante, en los años siguientes a esta conferencia "las actividades encaminadas a integrar el medio ambiente en los planes de desarrollo y en los procesos de adopción de decisiones en el plano nacional no llegaron muy lejos. Aunque se avanzó algo respecto de cuestiones científicas y técnicas, se siguió soslayando la cuestión del medio ambiente en el plano político y se fueron agravando, entre otros problemas ambientales, el agotamiento del ozono, el calentamiento de la Tierra y la degradación de los bosques" (Correa, 2003, 118).

En 1981 se presentó la primera Estrategia Mundial para la Conservación, realizada por la Unión In-

12 En esta Cumbre el desarrollo en sí mismo, no fue cuestionado. Se critica la producción y el orden económico internacional (Eschenhagen, 2006). 
ternacional para la Conservación de la Naturaleza (UICN) en colaboración con el Fondo Mundial para la Vida Silvestre (FMVS) y el Programa de las Naciones Unidas para el Medio Ambiente (PNUMA). En dicha estrategia se definió a la conservación como "la gestión de la utilización de la biosfera por el ser humano, de tal suerte que produzca el mayor y sostenido beneficio para las generaciones actuales, pero que mantenga su potencialidad para satisfacer las necesidades y las aspiraciones de las generaciones futuras" (Gudynas, 2002, 48)

De otro lado, en 1983 se creó la Comisión Mundial sobre el Medio Ambiente y el Desarrollo ${ }^{13}$, la cual publicó en 1987 el Informe Brundtland también conocido como Nuestro Futuro Común, en el cual se utiliza por primera vez el término Desarrollo Sostenible y se le define como aquel que "satisface las necesidades del presente sin comprometer la habilidad de las generaciones futuras para satisfacer sus propias necesidades" (WCED, 1987, citado en El Serafi, 1994, 107). Según el Informe Bruntland, el concepto de Desarrollo Sostenible "implica límites, no límites absolutos, sino limitaciones que imponen a los recursos del medio ambiente el estado actual de la tecnología y de la organización social y la capacidad de la biosfera de absorber los efectos de las actividades humanas-, pero tanto la tecnología como la organización social pueden ser ordenadas y mejoradas de manera que abran el camino a una nueva era de crecimiento económico" (Gudynas, 2002, 52).

De tal modo, en la conceptualización del Desarrollo Sostenible del Informe Brundtland se tocan varios puntos, uno referente a la importancia de considerar las necesidades de las generaciones futuras, otro referente al reconocimiento de los límites de la biosfera relacionados con la absorción de los impactos ambientales y otro relacionado a los límites que dependen del ser humano y por tanto se encuentran sujetos a su modificación, apartándose en este último punto de las opiniones del Club de Roma.
De este modo, con el Informe Brundtland la contradicción que hasta entonces existía entre conservación y crecimiento económico, como fruto de las advertencias del Club de Roma, fueron reinterpretadas hasta tal punto que la conservación ecológica que antes era vista como un obstáculo al crecimiento económico terminó por convertirse en un instrumento para asegurarlo. Más aún a partir de este informe la oposición entre ambiente y crecimiento desapareció al mismo tiempo que el propio concepto de límites se disipó, ante la idea de que dichos limites no eran absolutos sino que era posible su modificación mediante el uso de la tecnología (Gudynas, 2002).

En 1991 con la Segunda Estrategia Mundial para la Conservación, realizada por la Unión Internacional para la Conservación de la Naturaleza (UICN) en colaboración con el Fondo Mundial para la Vida Silvestre (FMVS) y el Programa de las Naciones Unidas para el Medio Ambiente (PNUMA), bajo el título de "Cuidar la Tierra", se definió al Desarrollo Sostenible como:

\begin{abstract}
"la mejora en la "calidad de vida humana sin rebasar la capacidad de carga de los ecosistemas que la sustentan (...) Esta estrategia deja en claro que un desarrollo de este tipo requiere profundos cambios culturales, $y$, con ese objetivo, propone nueve Principios para una "sociedad sostenible": respetar y cuidar la comunidad de los seres vivos, mejorar la calidad de la vida humana, conservar la biodiversidad, reducir al mínimo el agotamiento de los recursos no renovables, mantenerse dentro de la capacidad de carga de la Tierra modificar las actitudes y prácticas personales, facultar a las comunidades para que cuiden su propio ambiente, proporcionar un marco nacional para la integración del desarrollo y la conservación, y forjar una alianza mundial" (Gudynas, 2002, 54-55).
\end{abstract}

13 La comisión contó con 23 miembros bajo la presidencia de Noruega Gro Harlem Brundtland; los miembros latinoamericanos fueron Pablo González Casanova (un sociólogo mexicano que renunció antes de finalizar el trabajo), Margarita Merino de Botero (colombiana), Pablo Nogueira Neto (un ecólogo brasileño) y S. Rampal (político de Guyana)" (Gudynas, 2002, 52) 
De tal modo, dicha estrategia defendía un desarrollo centrado tanto en el bienestar de las personas como en la conservación y mantenimiento de la naturaleza, y del mismo modo se cuestionaba el término "crecimiento sostenible", en tanto que este se torna contradictorio en la medida que nada físico puede crecer de manera indefinida (Gudynas, 2002).

Posteriormente, la Asamblea General de las Naciones Unidas convocó a la Conferencia de las Naciones Unidas sobre el Medio Ambiente y el Desarrollo (CNUMAD) también conocida como la Cubre de la Tierra realizada en Rio de Janeiro en 1992, en ésta conferencia se aprobaron: (i) la Agenda 21, con la cual se buscó promover el Desarrollo Sostenible, (ii) la Declaración de Río sobre el Medio Ambiente y el Desarrollo, en la cual se establecen 27 principios que han de regir el comportamiento de las naciones en lo respectivo al ambiente y al desarrollo, y (iii) otros documentos sobre cambio climático, bosques y biodiversidad. Sin embargo, dichos tratados presentan problemas en cuanto que "las 2.500 recomendaciones de la Agenda 21 son dejadas a los buenos oficios de las ONG y al sponsoring (eventualmente subvencionado) de las firmas multinacionales, y la solución a los problemas de la contaminación (cambio climático y otros) se confían a las fuerzas del mercado" (Latouche, 2007, 39).

No obstante, pese a que la Cumbre de la Tierra

“(...) permitió firmar las convenciones en cambio climático y biodiversidad, (...) la implementación real de ellas ha dejado mucho que desear. (En tanto que) las regulaciones sobre la contaminación atmosférica, que desencadena el recalentamiento global, se han desarrollado bajo disputas con Estados Unidos (el principal contaminador planetario) abandonándose las negociaciones y dejando así enormes dudas sobre la futura implementación de un acuerdo. (Así mismo) más allá de estos y otros esfuerzos, todos los indicadores de la calidad ambiental señalan que el deterioro y la pérdida de biodiversidad avanzan; que hay muchas experiencias locales valiosas, que hay parques nacionales destacados y empresas reconocidas por innovaciones ecológicas...y así sucesivamente se pueden listar muchos ejemplos. Pero todos ellos son locales, están acotados y muchas veces dependen del empuje emprendedor de un puñado de personas. (En últimas) lo cierto es que no se ha llegado a implantar con éxito grandes cambios o nuevas estrategias a nivel nacional o internacional." (Gudynas, 2002, 57).

De otro lado, vale la pena señalar que esta conferencia se encuentra fuertemente influenciada por el Informe Brundtland, de ahí que se hable de Desarrollo Sostenible, un concepto en el cual se reconocen los límites de los recursos de la tierra y se manifiesta la necesidad de salvaguardarlos para las generaciones futuras, al mismo tiempo que se defiende el desarrollo económico como objetivo principal. Así pues, en esta conferencia se defiende la idea de seguir con el modelo económico de la época, caracterizado por la búsqueda del máximo crecimiento y rendimiento económico, pero considerando la necesidad de incluir en dicho modelo los factores ambientales. Esta cumbre se encuentra enmarcada bajo una tendencia economicista, en la cual no se critica la producción, el orden económico, ni el desarrollo, lo que se defiende es la búsqueda de un desarrollo económico que sea sostenible. De manera que, se elude el análisis profundo de la problemática ambiental y se omite el tema de la capacidad de regeneración de los recursos naturales (Eschenhagen, 2006).

Pese a todas las críticas existentes y la dicotomía que encierra la noción de desarrollo sostenible, a partir de ésta conferencia este concepto se instauró como el objetivo a perseguir a nivel internacional y se empezaron a desarrollar de manera continua diversas políticas, legislaciones, normas y acuerdos ambientales internacionales en pro del desarrollo sostenible.

Así mismo, en este mismo año (1992) fue redactado y presentado el nuevo informe Meadow, bajo el título "más allá de los límites", este último informe a diferencia del Primer Informe del Club de Roma presentado en 1972 por Meadows, bajo el título de "los límites del crecimiento", no cuestiona los conceptos de crecimiento y desarrollo, sino que busca hacerlos "sostenibles", defendiendo la idea de que 
el crecimiento sostenido, el equilibrio ambiental y la equidad son posibles mediante una adecuada gestión (Naredo, 1999).

En 2002 se realizó la Cumbre Mundial sobre el Desarrollo Sostenible en Johannesburgo, en la cual se dio continuidad a lo planteado 10 años atrás en la Cumbre de la Tierra respecto al Desarrollo Sostenible. No obstante, el escenario diplomático que rodeaba Johannesburgo "era complejo dada la negativa de EE.UU, a compromisos efectivos en los acuerdos comerciales, la complicidad de algunos países (específicamente los productores de petróleo) y un cierto cinismo de varios gobiernos (como era el caso de la Unión Europea al contar con la ventaja de que frente a Washington pocas medidas le bastaban para aparecer como más comprometida con el ambiente)" (Gudynas, 2002, 58).

De otro lado, la crisis económica y política de América Latina no permitió a los países que la conforman asumir posiciones de liderazgo. Sumado a lo anterior, otra situación problemática de dicha Cumbre se encontraba relacionada con el hecho de que el principal interés no fue el ambiente sino el Desarrollo Sostenible, por lo cual se realizaron sólo unas menciones muy marginales a lo específicamente ambiental, como se puede visualizar en los 34 puntos de la Cumbre, en donde sólo 6 hacen referencia a lo ambiental, pero no como punto principal sino supeditado al Desarrollo Sostenible, buscando que lo ambiental se direccione o se gestione en miras a contribuir con un Desarrollo Sostenible (Gudynas, 2002; Eschenhagen, 2006)

De ahí que, esta Cumbre es calificada por muchos como una "tragedia", un "fracaso", pues pese a que con el discurso del Desarrollo Sostenible presente en Johannesburgo, se pretendía buscar un equilibrio entre las esferas social, ambiental y económica; imponiendo un énfasis en la gestión ambiental que garantiza continuidad en los modelos de crecimiento, buscando la sostenibilidad del crecimiento económico y no la sustentabilidad ecológica (Eschenhagen, 2006).

Ahora bien, realizada una breve aproximación a la problemática ambiental y al surgimiento del Desarrollo Sostenible, es indispensable tratar más a fondo este concepto, analizar sus diferentes corrientes, y en últimas proponer una "alternativa" que escape del imaginario del desarrollo existente y posibilite el bienestar social y el equilibrio ecológico, lo cual es el objetivo del siguiente apartado.

\section{De la insustentabilidad del desarrollo sostenible a la sustentabilidad ambiental}

Como se mencionó en el apartado anterior la estrategia del Desarrollo Sostenible presentada en "Nuestro Futuro Común", fue la estrategia que reemplazó a la del "eco-desarrollo", esta situación fue posible en tanto que: (i) el Desarrollo Sostenible se presentó como un proyecto con el cual se erradicaría la pobreza y se salvaguardaría el ambiente (Escobar, 1996), y (ii) existió una amplia aceptación por parte de los economistas de la época del término debido a que éste se confundía con el de Desarrollo Autosostenido que fue introducido años atrás por Rostow bajo el cual se concebía al desarrollo como una serie de etapas a seguir para conseguir el "despegue" de la economía ${ }^{14}$ (Naredo, 1999).

En este sentido, cabe mencionar que el Desarrollo Sostenible se circunscribe en un proceso más amplio de problematización de la supervivencia global, el cual ha generado la reconstrucción de la relación entre naturaleza y sociedad. Esta problematización surgió como respuesta a dos situaciones, una de ellas relacionada con el enfoque destructivo que tuvo el desarrollo después de la Segunda Guerra Mundial, y la otra referente al auge que tuvieron los movimientos ambientalistas tanto en el Norte como el Sur, y

14 "Se hacía creer que todos los países, por muy subdesarrollados que fueran, si obraban juiciosamente, podrían entrar en fase de "despegue" (take off) y lanzarse al crecimiento rápido que les permitiría "acortar distancias" e incluso "alcanzar" a los países ricos o desarrollados. Los efectos de este mensaje fueron ideológicamente devastadores, al eclipsar los posibles proyectos de vida de sociedad diferentes que podían albergar países como la India de Gandhi, entre los países "no alineados", o como la China de Mao o la Rusia soviética, entre los países socialistas" (Naredo, 2006, 181) 
fruto del cual se produjo una internacionalización del ambiente (Escobar, 1996).

Ahora bien, pese a que el Desarrollo Sostenible comparte muchos principios con el discurso del ecodesarrollo, bajo el Desarrollo Sostenible "las estrategias de poder del orden económico dominante han ido transformando el discurso ambiental crítico para someterlo a los dictados de la globalización económica (hasta el punto que) el ambiente fue quedando atrapado en las mallas del poder del discurso del crecimiento sostenible" (Leff, 2000, 20). De forma que, el énfasis del discurso del Desarrollo Sostenible ésta en la gestión de la Tierra, es más con dicho discurso se asume una actitud sumamente gerencial, buscando la durabilidad de los modelos de crecimiento y desarrollo existentes, mediante el uso de estrategias de administración de la naturaleza (Escobar, 1996).

De igual manera, el concepto Desarrollo Sostenible encierra gran contradicción a su interior y puede ser catalogado como un oxímoron ${ }^{15}$, es decir una combinación de conceptos contradictorios o incongruentes (Naredo, 1999) en cuanto que busca reconstruir la relación sociedad - naturaleza sin interrogarse sobre la compatibilidad que puede existir entre el desarrollo y el ambiente, la cual puede ser inexistente o limitada en el mejor de los casos, esto debido a que para lograr el equilibrio ecológico se tendría que realizar una modificación del modelo económico de crecimiento y del estilo de vida preponderantes, lo cual debería conducir a otro paradigma de desarrollo o más bien a una alternativa "al" desarrollo (Latouche, 2007). Más aún, "la mayor parte de la indefinición actual procede del empeño de conciliar el crecimiento (o desarrollo) económico con la idea de sostenibilidad, cuando cada uno de estos dos conceptos se refieren a niveles de abstracción y sistemas de razonamiento diferentes: las nociones de crecimiento (y de desarrollo) económico encuentran su definición en los agregados monetarios homogéneos de "producción" y sus derivados que segrega la idea usual de sistema económico, mientras que la preocupación por la sostenibilidad recae sobre procesos físicos singulares y heterogéneos" (Naredo, 1999, 60).

Ahora bien, para ejemplarizar la ambigüedad y la contradicción que encierra el término Desarrollo Sostenible solo basta dar un vistazo al Informe Brundtland, en donde se indica en su párrafo 10 que el desarrollo sostenible sólo tendrá lugar a nivel mundial si los más poderoso adoptan un modo de vida respetuoso con los limites ecológicos de la Tierra, mientras al mismo tiempo afirma en unas páginas más adelante que por motivo del aumento en la tasa de crecimiento demográfico, la producción de manufacturas deberá incrementarse de 5 a 10 veces, para que así el consumo de bienes manufacturados en los países subdesarrollados pueda equiparse al de los países desarrollados (Informe Brundtland, 1987, citado en Latouche, 2007).

En este orden de ideas, surge la siguientes pregunta: ¿Cómo pensar en un modo de vida más respetuoso con el ambiente mientras se defiende la idea de aumentar cada vez más la producción?, simplemente no se puede, pues los logros que se alcancen en reducción de recursos en cada unidad producida (hacer más con menos) será compensado por el aumento de las unidades producidas, ocasionando que la escala de impacto sobre el ambiente se mantenga o se aumente en el peor de los casos. Así pues, se ha aumentado la productividad de los recursos naturales, pero el incremento de las unidades producidas, hace que dicho avances sea en últimas insuficiente para reducir el impacto sobre la Tierra (Latouche, 2007).

De tal modo, con el Desarrollo Sostenible no se ha buscado limitar el crecimiento económico y la explotación de la naturaleza, lo que se ha buscado es garantizar la sostenibilidad del desarrollo en términos económicos, llevando la explotación de los recursos naturales a niveles "prudentes" que aseguren la con-

15 "La ambivalencia del discurso de la sustentabilidad surge de la polisemia del término sustainability, que integra dos significados: uno, traducible como sustentable, que implica la internalización de las condiciones ecológicas de soporte del proceso económico; otro, que aduce a la durabilidad del proceso económico mismo" (Leff, 2000, 21). Así pues, el término inglés originario sustainability proveniente de los países anglosajones, tiene diferentes traducciones al español, entre las cuales sobresalen la sostenibilidad, la durabilidad o sustentabilidad (Naredo, 1999; Gudynas, 2002) 
tinuidad del modelo económico dominante, esto es, del desarrollo económico. Así las cosas, tener en cuenta al ambiente no significa necesariamente una preocupación verdadera por su salvaguarda. De hecho, acompañar el concepto desarrollo del adjetivo sostenible, "agregándole" así preocupaciones ecológicas, se ha realizado en la medida en que no atenta contra los intereses de los agentes económicos, y en tanto que la disponibilidad de recursos naturales en el largo plazo provee las condiciones necesarias para que se siga produciendo la acumulación económica y el desarrollo de las regiones más poderosas (Latouche, 2007).

En suma, siguiendo a Escobar (1996; 1999) dentro de las principales críticas al discurso del Desarrollo Sostenible se encuentran las siguientes:

- No problematiza la sostenibilidad de las culturas locales y sus realidades, sino que hace referencia a la sostenibilidad del ecosistema global, lo cual lleva a una homogeneización de los problemas ambientales que oscurece las diferencias existentes en los problemas ecológicos de cada región (Escobar, 1996).

- Visibiliza y resalta la culpa de las actividades "degradantes" de los pobres, oscureciendo la culpa de los contaminadores industriales de Norte y Sur, y de los estilos de vida depredadores propios del desarrollo capitalista (Escobar, 1996).

- Se presenta a la pobreza como causa de la degradación ambiental y por ende se promociona al crecimiento económico con la solución a la problemática ambiental, en tanto que con el crecimiento se eliminará la pobreza (Escobar, 1996).

- Reconcilia dos objetivos contradictorios y hasta enemigos, esto es, crecimiento y cuidado del ambiente, defendiendo la idea de que la armonización de ambos es posible mediante el establecimiento de nuevas formas de gestión, dicha gestión debe propender por sostener el crecimiento económico y no el ambiente (Escobar, 1996).
- Considera como un hecho la escasez de los recursos naturales y por tanto centra la atención en la búsqueda de alternativas más eficientes de usar los recursos naturales sin amenazar la supervivencia de las personas y del ambiente, en últimas, lo que se busca es producir más con menos, reduciendo los problemas ecológicos a problemas de "eficiencia" (Escobar, 1996; 1999).

- Da por sentadas una serie de construcciones de la modernidad liberal de Occidente, tales como la presunción de la existencia de un conocimiento científico objetivo, la creencia de que el mundo es algo externo al observador y por tanto es posible su conocimiento y control por parte de los sujetos, la idea de que la realidad social puede "gestionarse" y el cambio social "planificarse" (Escobar, 1999).

Ahora bien, a pesar de las problemáticas en torno al concepto de desarrollo sostenible mencionadas, este término consiguió incorporarse en el discurso económico debido a su "elasticidad y a sus numerosas metamorfosis... (Así pues) el desarrollo sostenible parece cambiar de forma y de significado según los contextos y las personas que lo utilizan" (Boiral, 2005, 7). Más aún, "circulan docenas de definiciones entre expertos y políticos, porque detrás de la idea clave se esconden muchos y diversos intereses y visiones. Como tan frecuentemente ocurre, profundas controversias políticas y ética hacen de la definición de este concepto una arena de lucha" (Sachs, 1996, 22).

De tal modo, existen diferentes perspectivas teóricas para caracterizar el concepto de desarrollo sostenible, ninguna de la cuales tiene la autoridad sobre las demás para conceptualizar dicho término, situación que evidencia la ambigüedad que encierra este concepto. A continuación en la Tabla 4 se describen las perspectivas teóricas más relevantes que abordan el desarrollo sostenible. 
Tabla 4. Perspectivas teóricas más relevantes que abordan el desarrollo sostenible ${ }^{16}$

\begin{tabular}{|c|c|}
\hline Teoría & Caracterización del desarrollo sostenible \\
\hline $\begin{array}{l}\text { Neoclásica- } \\
\text { Equilibrio }\end{array}$ & $\begin{array}{l}\text { Bienestar no decreciente (antropocéntrico); creci- } \\
\text { miento sostenible basado en tecnología y substi- } \\
\text { tución; optimiza las externalidades ambientales; } \\
\text { mantiene el acervo agregado de capital natural y } \\
\text { económico; los objetivos individuales prevalecen } \\
\text { sobre las metas sociales; la política se aplica cuan- } \\
\text { do los objetivos individuales entran en conflicto; la } \\
\text { política de largo plazo se basa en soluciones de } \\
\text { mercado }\end{array}$ \\
\hline $\begin{array}{l}\text { Neoaustríaca- } \\
\text { Temporal }\end{array}$ & $\begin{array}{l}\text { Secuencia teológica de adaptación consciente y } \\
\text { orientada al logro de las metas; previene los pa- } \\
\text { trones irreversibles; mantiene el nivel de la orga- } \\
\text { nización (neguentropía) del sistema económico; } \\
\text { optimiza los procesos dinámicos de extracción, } \\
\text { producción, consumo, reciclaje y tratamiento de } \\
\text { desechos }\end{array}$ \\
\hline $\begin{array}{l}\text { Ecológico - } \\
\text { Evolutiva }\end{array}$ & $\begin{array}{l}\text { Mantiene la resiliencia de los sistemas naturales, } \\
\text { contemplando márgenes para fluctuaciones y ci- } \\
\text { clos (destrucción periódica); aprende de la incer- } \\
\text { tidumbre de los procesos naturales; no dominio de } \\
\text { las cadenas alimentarias por los seres humanos; } \\
\text { fomento de la diversidad genética/biótica/eco- } \\
\text { sistémica; flujo equilibrado de nutrientes en los } \\
\text { ecosistemas }\end{array}$ \\
\hline $\begin{array}{l}\text { Tecnológico- } \\
\text { Evolutiva }\end{array}$ & $\begin{array}{l}\text { Mantiene la capacidad de adaptación co-evolutiva } \\
\text { en términos de conocimientos y tecnología para re- } \\
\text { accionar a la incertidumbre; fomenta la diversidad } \\
\text { económica de actores, sectores y tecnologías }\end{array}$ \\
\hline Físico-Económica & $\begin{array}{l}\text { Restringe los flujos de materiales y energía hacia y } \\
\text { desde la economía: metabolismo industrial basado } \\
\text { en política de cadena materiales-producto: inte- } \\
\text { gración de tratamiento de desechos, mitigación, } \\
\text { reciclado y desarrollo de productos }\end{array}$ \\
\hline $\begin{array}{l}\text { Biofísico - } \\
\text { Energética }\end{array}$ & $\begin{array}{l}\text { Estado estacionario con transflujo de materiales y } \\
\text { energía mínimo; mantiene el acervo físico y bio- } \\
\text { lógico y la biodiversidad; transición a sistemas } \\
\text { energéticos que producen un mínimo de efectos } \\
\text { contaminantes }\end{array}$ \\
\hline $\begin{array}{l}\text { Sistémico - } \\
\text { Ecológica }\end{array}$ & $\begin{array}{l}\text { Control de los efectos humanos directos e indirectos } \\
\text { sobre los ecosistemas; equilibrio entre los insumos } \\
\text { y productos materiales de los sistemas humanos; } \\
\text { minimización de los factores de perturbación de los } \\
\text { ecosistemas, tanto locales como globales }\end{array}$ \\
\hline
\end{tabular}

\begin{tabular}{|c|c|}
\hline $\begin{array}{l}\text { Ingeniería } \\
\text { ecológica }\end{array}$ & $\begin{array}{l}\text { Integración de las ventajas humanas y de la calidad } \\
\text { y funciones ambientales mediante el manejo de los } \\
\text { ecosistema; diseño y mejoramiento de las solucio- } \\
\text { nes ingenieriles en la frontera entre la economía, la } \\
\text { tecnología y los ecosistemas; aprovechamiento de } \\
\text { la resiliencia, la auto-organización, la autorregula- } \\
\text { ción y las funciones de los sistemas naturales para } \\
\text { fines humanos }\end{array}$ \\
\hline Ecología humana & $\begin{array}{l}\text { Permanencia dentro de la capacidad de carga (cre- } \\
\text { cimiento logístico); escala limitada de la economía } \\
\text { y la población; consumo }\end{array}$ \\
\hline Socio-biológica & $\begin{array}{l}\text { Conservación del sistema cultural y social de in- } \\
\text { teracciones con los ecosistemas; respeto por la } \\
\text { naturaleza integrado en la cultura; importancia de } \\
\text { la supervivencia del grupo }\end{array}$ \\
\hline $\begin{array}{l}\text { Histórico- } \\
\text { institucional }\end{array}$ & $\begin{array}{l}\text { Igual atención a los intereses de la naturaleza, los } \\
\text { sectores y las generaciones futuras; integración de } \\
\text { los arreglos institucionales en las políticas econó- } \\
\text { micas y ambientales; creación de apoyo institucio- } \\
\text { nal de largo plazo a los intereses de la naturaleza; } \\
\text { soluciones holísticas y no parciales, basada en una } \\
\text { jerarquía de valores }\end{array}$ \\
\hline Ético- utópica & $\begin{array}{l}\text { Nuevos sistemas individuales de valor (respeto por } \\
\text { la naturaleza y las generaciones futuras, satisfac- } \\
\text { ción de las necesidades básicas) y nuevos objeti- } \\
\text { vos sociales (estado estacionario); atención equili- } \\
\text { brada a la eficiencia, distribución y escala; fomento } \\
\text { de actividades en pequeña escala y control de los } \\
\text { efectos secundarios ("lo pequeño es hermoso"); } \\
\text { política de largo plazo basada en valores cambian- } \\
\text { tes y estimulante del comportamiento ciudadano } \\
\text { (altruista) en contraposición al comportamiento } \\
\text { individualista (egoísta). }\end{array}$ \\
\hline
\end{tabular}

En las definiciones de desarrollo sostenible abordadas en la tabla 4 se pueden vislumbrar dos corrientes. Una corriente comprende aquellas definiciones que enfatizan en lo ecológico centrándose en la capacidad de recuperación de la naturaleza más que en la capacidad de producción de bienes. En la otra corriente se encuentran las definiciones que se orientan más a lo económico, las cuales consideran que el desarrollo es sostenible cuando se puede sostener el bienestar económico, el consumo o el capital (Gallopín, 2003).

16 Fuente: Bergh \& Jeroen (1996), citados en Gallopín (2003, 25-26). 
La definición de DS más citada en la literatura es la de la Comisión Bruntland, la cual data del año 1987 y en la cual se define DS como aquel que "satisface las necesidades del presente sin comprometer la capacidad de las generaciones futuras de satisfacer las propias" (Wced, 1987, citado en El Serafi, 1994, p.107). Con esta definición se pretendía promover tanto la sostenibilidad ambiental como la justifica internacional. Pero al examinar esta definición de desarrollo sostenible a fondo se encuentra que "está diseñada para maximizar los consensos más que la claridad. Como con cualquier compromiso, esto no es un logro pequeño, ya que la definición funciona como un cemento que pega todas las partes, a amigos y enemigos por igual" (Sachs, 1996, 22). Así pues, esta definición presenta un gran problema, en la medida que:

- Habla en términos generales de satisfacer las necesidades presentes, sin entrar en detalles sobre a qué necesidades se refiere, con lo cual se deja de lado el debate de la justicia en la actualidad.

- Subyace a esta definición la idea de equidad entre generaciones, sin que se especifique que se entiende por tal y que implicaciones tiene para la generación actual.

- No tiene en cuenta las diferencias existentes entre países desarrollados y "subdesarrollados", estableciendo para ambos los mismos tipos de compromisos.

- Entre más global y amplia es la definición el DS será menos limitante y comprometedora para los distintos países, pues el término será más manejable por los distintos gobiernos en tanto conserve su elasticidad conceptual y en tanto no precise los cambios que se deben realizar (Boiral, 2005).

En suma, bajo esta definición de desarrollo sostenible

“(...) permanecen abiertas dos preguntas cruciales; ¿Cuáles necesidades? ¿Las necesidades de quién?. Dejar estas preguntas pendientes en un mundo dividido significa hacer a un lado la crisis de la justicia. ¿El desarrollo sostenible" supuestamente debe solucionar las necesidades de agua, tierra y seguridad económica, o las necesidades de viajes aéreos y depósitos de los bancos? ¿Se preocupa de las necesidades de supervivencia o las necesidades de lujo? ¿Son las necesidades en cuestión las de la clase de consumidores o aquellas de la enorme cantidad de desposeídos?. El Informe Brundtland es indeciso en todo el texto, $y$ en consecuencia evita enfrentar la crisis de la justicia. "(Sachs, 1996, 23).

De otro lado, teniendo en cuenta que en la práctica bajo el concepto de desarrollo sostenible se ha buscado oscurecer que se está tratando de sostener el crecimiento económico y no el ambiente. El desarrollo sostenible se enmarcaría bajo la sostenibilidad débil propuesta por Norton (1992, citado en Naredo, 1999) en tanto que propende por un enfoque monetario que sigue privilegiando al crecimiento económico como objetivo a perseguir, y que hace del ambiente un apéndice, un recurso a ser gestionado para alcanzar no el sostenimiento ambiental sino el sostenimiento del crecimiento económico. Más aún, bajo la sostenibilidad débil no se considera la dependencia de la economía de los procesos y sistemas ecológicos, y por tanto no se busca el sostenimiento del ambiente.

No obstante, según Norton (1992, citado en Naredo, 1999) existe otro tipo de sostenibilidad, esta es, la fuerte. Los autores que se enmarcan bajo la corriente "fuerte" comprenden que la idea de sostenibilidad demanda la ampliación y reformulación de la idea estándar de sistema económico y no solamente un retoque de la misma. Es más, bajo la sostenibilidad fuerte se reconoce que el "capital natural" en su mayoría no es sustituible por el capital fabricado por el hombre, razón por la cual es indispensable evitar su deterioro, tornándose de relevancia la salud ecosistémica y la modificación del sistema actual de valores (Naredo, 1999).

Dentro de las propuestas enmarcadas bajo la sostenibilidad fuerte se puede ubicar la sustentabilidad ecológica basada en una racionalidad ambiental de 
Leff (2000), la cual debe conllevar nuevos principios éticos, valores culturales y potenciales productivos (Latouche, 2007; Leff, 2000). Dicha sustentabilidad deberá fundarse en una política de la diversidad y la diferencia e implicará "bajar de su pedestal al régimen universal y dominante del mercado como medida de todas las cosas, como principio organizador del mundo globalizado y del sentido mismo de la existencia humana" (Leff, 2008, 33), en tanto que a toda política de la diferencia subyace el principio de la inconmensurabilidad, pues "los tiempos y los potenciales ecológicos, las condiciones ecológicas de sustentabilidad y los sentidos existenciales de los pueblos, son procesos difícilmente convertibles en valores de mercado; no es posible asignar un precio a estos valores simbólicos y procesos de largo plazo para los cuales no hay una tasa de descuento real que pueda traducirlos en valores económicos actuales" (Leff, 2008, 33).

Ante este escenario, en el presente artículo se propone como alternativa al uso del concepto de desarrollo sostenible, el de sustentabilidad ecológica sin añadirle el término desarrollo, pues como se mencionó en párrafos anteriores el desarrollo siempre propenderá por el crecimiento económico por encima de la sustentabilidad ecológica, y por tanto la expresión desarrollo sostenible no deja de ser un oxímoron que termina combinando dos conceptos totalmente opuestos: desarrollo en términos de crecimiento económico y sustentabilidad ecológica, supeditando está última al crecimiento.

Adicionalmente, se considera más adecuado el uso de los términos "sustentabilidad ambiental" o simplemente "sustentabilidad", debido a la polisemia del concepto de sostenibilidad, el cual primero surgió en los países anglosajones como "sustainability" en inglés, e incorpora dos significados diferentes: el primero de ellos traducible como sustentable implicando la internalización de las condiciones ecológicas en las cuales se soporta el proceso económico; y el otro, traducible como sostenible, refiriéndose a la durabilidad del proceso económico mismo (Leff 2000). De manera que, cuando se hable de sustentabilidad ambiental se está haciendo referencia a la sostenibilidad fuerte de Norton (1992, citado en Naredo, 1999), la cual ha de basarse en una racionali- dad ambiental que conlleve nuevos principios éticos, valores culturales y potenciales productivos (Latouche, 2007; Leff, 2000).

Se adopta la propuesta de una sustentabilidad ecológica basada en una racionalidad ambiental que lleve a repensar la producción y generar "una reorganización de la producción basada en el potencial productivo de la naturaleza, el poder de la ciencia y la tecnología modernas, y los procesos de significación que definen identidades culturales y sentidos existenciales de los pueblos en formas diversas de relación entre los seres humanos y la naturaleza" (Leff, 2000, 38). Esto debido a que la articulación sinérgica de los procesos de producción con: los potenciales ecológicos de la naturaleza, la ciencia, la tecnología y los significados asignados por los seres humanos a la naturaleza, hará que los procesos productivos en realidad sean sustentables y abiertos a la variedad cultural (Leff, 2004).

Dicha sustentabilidad ecológica sustentada en una racionalidad ambiental trasciende los valores de mercado al enmarcarse en una política de la diversidad y diferencia, bajo la cual se reconoce y valoriza la naturaleza desde una pluralidad de racionalidades $e$ identidades, es decir, desde diversos códigos culturales (Leff, 2008). Más aún, la racionalidad ambiental se aparta de la concepción productivista del ambiente buscando "convertirse en una estrategia para la reapropiación social de la naturaleza, basada en la valorización cultural, económica y tecnológica de los bienes y servicios ambientales de la naturaleza, (que genera) una política del ser, de la diversidad y de la diferencia que replantea el valor de la naturaleza y el sentido de la producción" (Leff, 2004, 43).

Más aún, una sustentabilidad ambiental basada en la diversidad cultural y en los potenciales de la naturaleza defiende la pluralidad cultural, la diversidad de valores en los distintos contextos ecológicos y la conservación de la identidad de los diferentes pueblos, esto debido a que se concibe la naturaleza como un ente integrado y sinérgico, en lugar de concebirla como un acervo de capital (Leff, Argueta, Boegue \& Porto, 2002). La ventaja de adherirse a la sustentabilidad ambiental en lugar de seguir con el imaginario del desarrollo sostenible es que permite gestionar 
mejor la producción, ya que mediante las estrategias de la sustentabilidad se buscará que la producción se diversifique y ajuste a los contextos y potenciales ecológicos de las distintas regiones.

Cabe señalar que, para el impulso de los potenciales ambientales de cada país la cultura es un pilar de suma relevancia, puesto que las construcciones culturales son las que regulan la extracción y empleo de los recursos por parte de los individuos que componen la sociedad para satisfacer sus respectivas necesidades -la cultura asigna significados y valores a los individuos en relación a lo ambiental- con lo cual inherentemente se delineará: el ritmo de extracción de los recursos naturales, la tecnología empleada y el acceso y transformación social de los recursos naturales (Leff, Argueta, Boegue \& Porto, 2002).

Por tanto, la cultura es "un principio activo para el desarrollo de las fuerzas productivas, en un paradigma alternativo de sustentabilidad; la productividad ecológica y la innovación tecnológica están entretejidas con procesos culturales que definen la productividad social de cada comunidad; y éstas, a su vez, se enlazan para generar una economía global alternativa, fundada en las fuerzas productivas de la naturaleza y en los sentidos creativos de la cultura" (Leff 1993, 1994a; citados en: Leff, Argueta, Boegue \& Porto, 2002, 497). Así pues, una conservación exitosa y sustentable sólo puede lograrse sobre la base de un examen cuidadoso del conocimiento local y de los potenciales de la naturaleza (Escobar, 1997). En suma:

- Con la sustentabilidad ambiental y una racionalidad ecológica se debe propender por "prácticas agrícolas de preservación de los procesos ecológicos, de protección de la erosión y mantenimiento de la fertilidad del suelo; de conservación de la diversidad genética y biológica; de regeneración selectiva de especies útiles; de manejo integrado de recursos naturales silvestres y especies cultivadas; y de innovación de sistemas agroecológicos altamente productivos" (Leff, Argueta, Boegue \& Porto, 2002, 498).

- Una verdadera alternativa al paradigma dominante del desarrollo emergerá como resultado del empoderamiento de la sociedad civil, y esto a su vez conllevará cambios en las relaciones sociales y políticas (Little \& Painter, 1995).

\section{Conclusiones}

Entre 1945-1955 surgió el concepto de países "subdesarrollados" y se empezaron a ver a países de los continentes de Asia, África y Latinoamérica como áreas con niveles alarmantes de pobreza. Por tanto, los problemas crónicos de pobreza de estos países empezaron a ocupar un espacio importante en la esfera internacional, pues se consideraba también que la prosperidad del Primer Mundo no podía perdurar en el tiempo si el Tercer Mundo seguía viviendo en condiciones de pobreza y malestar social. En este periodo se medía el nivel de desarrollo de un país únicamente mediante el PNB, y por ello la solución a la pobreza que vivían los países subdesarrollados era aumentar ese PNB. Para aumentar este indicador se consideraba clave insertar tecnología y capital a los países tercermundistas. Así pues, en este periodo se trabajó en aumentar el crecimiento económico a través de la industrialización.

La idea de desarrollo fue formulada inicialmente en Estados Unidos y Europa en los años posteriores al final de la Segunda Guerra Mundial, y a partir de ese momento se traslapó a los países del Tercer Mundo. Sin embargo, la introducción de este concepto en Asia, África y Latinoamérica resultó contracultural en tanto que se impuso en el imaginario de estos países la idea de progresar, de desarrollarse, de crecer en términos económicos, sin tener presente todos los procesos sociales, históricos, etc. que tuvieron que vivir los países de Primer Mundo para llegar a ciertos niveles de desarrollo. En este sentido, se impuso la idea de la existencia de una serie de etapas para llegar al despegue de una economía. De tal modo, con el proyecto desarrollista se planteó generar una transformación cultural total de Asia, África y Latinoamérica en consonancia con las lógicas del Primer Mundo, buscando eliminar las filosofías ancestrales y desintegrar las instituciones sociales existentes en los países del Tercer Mundo.

Pese a que a la postre lo que se ha logrado con el desarrollo es multiplicar los problemas del Tercer 
Mundo e incrementar la heteronomía en menoscabo de la autonomía de las sociedades, a comienzos de la década de 1950 la idea de transformar a Asia, África y Latinoamérica conforme a los mandatos de los países del Primer Mundo ya se encontraba inserta y predominaba en los círculos de poder. Y a finales de la década de 1970 el tipo de desarrollo que debía insertarse en los países del tercer mundo para resolver los problemas sociales de aquellas regiones fue la principal preocupación para teóricos y políticos.

Ahora bien, en este mismo periodo se vislumbró una corriente que rechazaba la idea de un desarrollo soportado sobre las estrategias capitalistas de la época, proponiendo en cambio otros tipos de desarrollos como el "social", el "participativo", el "local", el "sostenible", o simplemente "otro" desarrollo. Sin embargo, estas propuestas tenían problemas de fondo en tanto no cuestionaban al desarrollo medido en términos económicos sino que proponían modificaciones al desarrollo existente, sin que ello implicara salirse del ideario del crecimiento económico. A este proceso se le conoce como "eufemización por adjetivo", y mediante él se agregaba un adjetivo "social", "humano", "sostenible", "local", etc. al concepto de desarrollo. Pero estos adjetivos no eran más que mascaras del desarrollo.

En el presente documento se realizó énfasis en una de las mutaciones del desarrollo, esto es en el desarrollo sostenible, y como resultado del análisis se encontró que el desarrollo sostenible: no problematiza la sostenibilidad de las culturas locales sino que busca la homogeneización de las problemáticas ambientales omitiendo las diferencias existentes entre los contextos locales de cada región, enaltece la culpa de las actividades degradantes de los pobres mientras oscurece la culpa de los países contaminadores del Primer Mundo, considera a la pobreza como el principal problema del subdesarrollo y degradación ambiental promocionando al crecimiento económico como la solución a los problemas de pobreza, vincula dos conceptos contradictorios como son crecimiento económico con cuidado del ambiente, busca producir más con menos, convirtiendo los problemas ambientales en problemas de eficiencia, da por sentado una serie de construcciones de la modernidad liberal de Occidente, etc.
Ante este escenario, en el presente artículo se propone como alternativa al uso del concepto de desarrollo sostenible, el de sustentabilidad ecológica sin añadirle el término desarrollo, pues como se mencionó a lo largo del documento, el desarrollo siempre propenderá por el crecimiento económico por encima de la sustentabilidad ecológica, y por tanto la expresión desarrollo sostenible no deja de ser un oxímoron que termina combinando dos conceptos totalmente opuestos: desarrollo en términos de crecimiento económico y sustentabilidad ecológica, supeditando está última al crecimiento.

La ventaja de adherirse a la sustentabilidad ambiental en lugar de seguir con el imaginario del desarrollo sostenible es que permitiría gestionar mejor la producción, ya que mediante las estrategias de la sustentabilidad se buscará que la producción se diversifique y ajuste a los contextos y potenciales ecológicos de las distintas regiones.

Para finalizar cabe mencionar que la importancia del presente trabajo, a pesar de las limitaciones propias del enfoque de revisión bibliográfica adoptado, radica en el análisis de un concepto tan polisémico con lo es el desarrollo sostenible y la propuesta de la sustentabilidad como alternativa al mismo. Este análisis es importante tanto para académicos como para gobernantes y sociedad en general en la medida que se resalta y evidencia a través de un recorrido histórico y crítico por los conceptos "desarrollo" y "desarrollo sostenible" que el gran reto ante la crisis ambiental no es extender la racionalidad económica a las distintas esferas de la vida (social y ecológica), como se ha querido hacer con el desarrollo sostenible, sino que el verdadero reto se encuentra en estructurar otro tipo de economía, otra concepción del progreso, otra concepción de la riqueza, otra concepción de pobreza, en definitiva no se requiere una alternativa de desarrollo que se siga sustentando en la misma racionalidad economicista, sino que es indispensable abordar alternativas al desarrollo que se sustenten bajo lógicas diferentes.

De otro lado, teniendo en cuenta que para generar cambios en la práctica es importante plasmar primero a nivel teórico las problemáticas existentes en las prácticas, las visiones de mundo y las maneras de 
proceder actuales, para luego poder estudiar la manera más apropiada de mejorar dichas prácticas, en el presente artículo se trabajó la problemática existente en torno al término desarrollo sostenible, buscando la comprensión del porqué es indispensable trascender los idearios que encierra dicho concepto hacia alternativas al desarrollo, para que con dichas alternativas a la postre se gestione mejor la producción, respetando la diversidad cultural y la variedad de contextos ecológicos de las distintas regiones.

\section{Referencias}

Arroyo, F., Camarero, C. \& Vásquez, C. (1997). Análisis de los problemas medio ambientales. En: Ballesteros et al. Sociedad y Medio Ambiente. Madrid, Editorial Trotta; 49-81.

Boiral, O. (2005). "Desarrollo sostenible y gestión medio ambiental, o el efecto "Torre de Babel"” (Jiménez, M; trad.). En: Nuevo pensamiento administrativo. Compilador: Cruz, F. Editorial: Universidad del Valle, Cali, Colombia: 165-180.

Correa, F. (2003). "La compatibilidad entre el crecimiento económico y el medio ambiente: dos propuestas desde la economía". En: Ensayos de Economía, 12 (22): 117 - 141.

El Serafi, S. (1994). "Sostenibilidad, medida de ingreso y crecimiento". En: Desarrollo Económico Sostenible. Avances sobre el Informe Brundtland. Bogotá. Uniandes, Tercer Mundo: 107-129.

Eschenhagen, M. (2006). "Las cumbres ambientales internacionales y la educación ambiental". En: Revista OASIS, 12 (1): 39-76.

Eschenhagen, M. (2001). "Argumentos para repensar el "desarrollo"”. En: Innovar, Revista de Ciencias Administrativas y Sociales, (17): 109-122.

Escobar, A. (1999). "El desarrollo sostenible: dialogo de discursos". En: El final del salvaje. Naturaleza, cultura y política en la antropología moderna, Bogotá, Instituto Colombiano de Antropología e Historia y Centro de Estudios de la Realidad Colombiana: 75-96.

Escobar, A. (1997). Anthropology and Development. En: International Social Science Journal, 154: 497-515.

Escobar, A. (1996). La invención del tercer mundo. Construcción y deconstrucción del desarrollo. Bogotá. Norma S. A.

Galeano, E. (2011), Las venas abiertas de América Latina. Tercera Edición, Sexta reimpresión, Siglo XXI de España Editores.

Gallopín, G. (2003). Sostenibilidad y desarrollo sostenible: un enfoque sistémico. En: Serie Medio Ambiente y Desarrollo, No. 64. División de desarrollo Sostenible y Asentamientos Humanos. Naciones Unidas-Cepal-ECLAC, Santiago de Chile.

Gudynas, E. (2002). "Una mirada histórica al desarrollo sustentable”. En: Ecología, economía y ética del Desarrollo Sostenible. Segunda Edición. Buenos Aires, Argentina, Universidad Nacional del Comahue, Escuela M. Vilte de CTERA y CLAES: 45-59
Guimares, R. \& Barcena, A. (2002). "El desarrollo sustentable en América Latina y el Caribe desde Río 1992 y los nuevos imperativos de institucionalidad". En: La transición hacia el desarrollo sustentable. Perspectivas de América Latina y el Caribe. Universidad Autónoma latinoamericana: México: 15-34.

Latouche, S. (2007). Sobrevivir al desarrollo. Barcelona. Icaria editorial.

Leff, E. (2008). Discursos Sustentables. Primera edición. Siglo XXI Editores. México.

Leff, E. (2004). Racionalidad Ambiental. La reapropiación social de la naturaleza. Primera edición. Siglo XXI Editores, México.

Leff, E. (2000). "Globalización, ambiente y sustentabilidad del desarrollo". En: Saber Ambiental: Sustentabilidad, Racionalidad, Complejidad, Poder. Segunda edición. México. Siglo XXI editores en coedición con el Centro de Investigaciones Interdisciplinarias en Ciencias y Humanidades UNAM, y con PNUMA: 17-30.

Leff, E., Argueta, A., Boegue, E. \& Porto, C (2002). "Más allá del desarrollo sostenible: la construcción de una racionalidad ambiental para la sustentabilidad: una visión desde América". En: La transición hacia el desarrollo sustentable. Perspectivas de América Latina y el Caribe. Universidad Autónoma latinoamericana: México: 477-576.

Little, D. \& Painter, M. (1995). "Discourse, Politics, and the Development Process: Reflections on Escobar's Anthropology and the Development Encounter". En: American Ethnologist 22 (3): 602-609.

Ludevid, M. (2000). Capítulo II. La estrategia Ambiental de la Empresa. En: Gestión Medioambiental de la Empresa. Barcelona: Ariel: 46-64.

Naredo, J. (2006). Raíces económicas del deterioro ecológico y social. Más allá de los dogmas, España, Siglo XXI de España Editores, S.A.

Naredo, J. (1999). "Sobre la sostenibilidad de los sistemas". En: Naredo, J.M. \& Valero, A. (dirs.). Desarrollo económico y deterioro ecológico, Madrid, Fundación Argentaria y Visor Distribuciones: 57-70

Pierri, N. (2005). Historia del concepto de desarrollo sustentable. En: ¿Sustentabilidad? Desacuerdos sobre el desarrollo sustentable. Colección América Latina y el Nuevo Orden Mundial. México: 27-81.

Rogers, E. (1976). "Communications and Development: The passing of the dominant paradigm". En: Gumucio-Dragón A. \& Tutle, T. (comp.) Communication Research 3. Publicado en la Antología de Comunicación para el Cambio Social. Lecturas históricas y contemporáneas: 200-220.

Sabogal, J. \& Hurtado, E. (2009). "La historia se repite: una visión del desarrollo y del desarrollo sostenible". En: Revista Facultad de Ciencias Económicas: Investigación y Reflexión, 17(1): 195-216.

Sachs, W. (1996). "La anatomía política del desarrollo sostenible". En: La gallina de los huevos de oro: debate sobre el concepto de desarrollo sostenible, CEREC: 15-41. 